\title{
Concurrent primary hyperparathyroidism and pheochromocytoma in a Chinese lady with neurofibromatosis type 1
}

\author{
Cheuk-Lik Wong, Chun-Kit Fok and Vicki Ho-Kee Tam \\ Department of Medicine and Geriatrics, Caritas Medical Centre, Shamshuipo, Kowloon, Hong Kong SAR
}

Correspondence

should be addressed

to C-L Wong

Email

wcl264@ha.org.hk

\section{Summary}

We report a case of elderly Chinese lady with neurofibromatosis type-1 presenting with longstanding palpitation, paroxysmal hypertension and osteoporosis. Biochemical testing showed mild hypercalcaemia with non-suppressed parathyroid hormone level suggestive of primary hyperparathyroidism, and mildly elevated urinary fractionated normetanephrine and plasma-free normetanephrine pointing to a catecholamine-secreting pheochromocytoma/ paraganglioma. Further scintigraphic investigation revealed evidence of a solitary parathyroid adenoma causing primary hyperparathyroidism and a left pheochromocytoma. Resection of the parathyroid adenoma and pheochromocytoma resulted in normalization of biochemical abnormalities and hypertension. The rare concurrence of primary hyperparathyroidism and pheochromocytoma in neurofibromatosis type-1 is discussed.

\section{Learning points:}

- All NF-1 patients who have symptoms suggestive of a pheochromocytoma/paraganglioma (PPGL), even remotely, should undergo biochemical testing.

- The initial biochemical tests of choice for PPGL in NF-1 are either plasma-free metanephrines or urinary fractionated metanephrines. Any elevations of metanephrines should be carefully evaluated for the presence of PPGLs in NF-1 patients.

- Primary hyperparathyroidism (PHPT) is described in subjects with NF-1. Due to the lack of epidemiological and functional studies, their association is yet to be substantiated. Meanwhile, PHPT may further exacerbate the metabolic bone defect in these patients and should be treated when present according to published guidelines.

- Coexistence of PPGL and PHPT can occur in subjects with NF-1, mimicking multiple endocrine neoplasia type 2 (MEN2).

\section{Background}

Neurofibromatosis type-1 (NF-1) is a dominantly inherited genetic disorder with age-dependent penetrance and highly variable expressivity (1). The causative gene $N F 1$, located in $17 \mathrm{q} 11.2$, is a tumour suppressor gene, which encodes neurofibromin. Neurofibromin negatively regulates RAS by converting it from the active GTPbound form to the inactive GDP-bound form (2). Loss of neurofibromin results in hyperactivation of the RAS proto-oncogene, which is a key signalling molecule of cell growth. Therefore, NF-1 is now recognized as a form of RASopathy, where dysregulated RAS-MAPK signalling pathway causes cancer predisposition (3). Pheochromocytoma/paraganglioma (PPGL) is one of the most common endocrine neoplasia associated with NF-1 
and is observed in $0.1-14 \%$ of patients with NF-1 $(4,5$, $6,7)$. On the other hand, primary hyperparathyroidism has only been rarely reported as isolated cases and the majority is due to the presence of solitary parathyroid adenoma (8). Coexistence of pheochromocytoma and primary hyperparathyroidism (PHPT) was exceptional and may be mistaken as multiple endocrine neoplasia type 2 (MEN2). Clinicians should therefore remain vigilant of these endocrine manifestations and investigate for them especially in symptomatic patients.

\section{Case presentation}

A 65-year-old Chinese lady presented to our unit for palpitation for several years. She had been diagnosed with neurofibromatosis type 1 clinically since teenage. Her past medical history was notable for hyperlipidemia, osteoporosis and white coat hypertension. Her family history was notable for NF-1 in her daughter and son as well.

She first experienced on and off palpitation back in the year 2010. She described it as a fast, regular thumping sensation over the precordium which was mostly short-living and lasted no more than five to ten minutes. The symptom was worse when she had exertion and felt anxious. It was not associated with chest pain, dyspnoea, dizziness, sweating or pallor. Neither was there any precipitating factor. The symptom of palpitation was relatively mild initially and did not cause much impairment in her daily living. As a result, the patient did

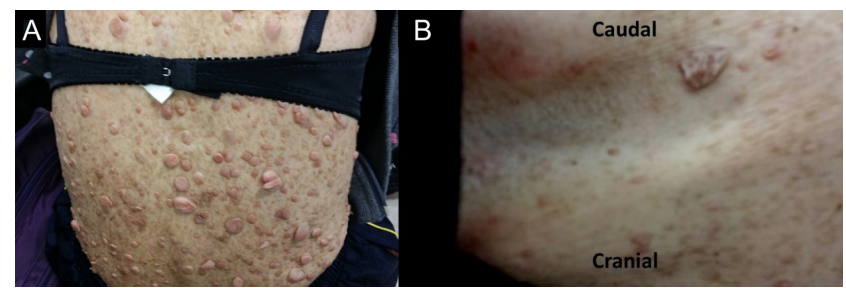

\section{Figure 1}

(A) Multiple cutaneous neurofibromata at the back of the patient. (B) Multiple axillary freckles over right armpit. (Pictures were taken with courtesy of our patient).

not seek medical advice till year 2013 when the paroxysms of palpitation became more troublesome.

Upon physical examination, the patient had multiple cutaneous neurofibromata over trunk and limbs, numerous café-au-lait spots and bilateral axillary freckling (Fig. 1). There was also presence of Lisch nodules bilaterally. Goitre was not present, and there was no sign of hyperthyroidism. Cardiovascular, respiratory and neurological examinations were all unremarkable. Office blood pressure was in the range of $130-160 \mathrm{mmHg}$ for systolic blood pressure and $75-90 \mathrm{mmHg}$ for diastolic blood pressure. Baseline ECG showed normal sinus rhythm. TSH and free T4 were normal. A 24-h Holter examination was performed, and apart from occasional supraventricular and ventricular ectopics $(<0.5 \%)$, no significant arrhythmia was detected. A 24-h urinary examination on catecholamines was normal in May 2014 (Table 1). The symptom of palpitation was initially attributed to anxiety.

Table 1 Biochemical testing of patient.

\begin{tabular}{l}
\hline Tests \\
\hline Calcium mmol/L \\
Phosphate $\mathrm{mmol} / \mathrm{L}$ \\
Albumin $/ \mathrm{L}$ \\
$24 \mathrm{~h}$ urine calcium $\mathrm{mmol} / 24 \mathrm{~h}$ \\
$\mathrm{PTH}$ pmol/L \\
24-h urinary FC and MN \\
$\mathrm{NE} \mathrm{nmol} / 24 \mathrm{~h}$ \\
$\mathrm{EPInmol} / 24 \mathrm{~h}$ \\
$\mathrm{NMN} \mathrm{nmol} / 24 \mathrm{~h}$ \\
$\mathrm{MN} \mathrm{nmol} / 24 \mathrm{~h}$ \\
$\mathrm{Plasma}-\mathrm{free} \mathrm{MN}$ \\
$\mathrm{NMN} \mathrm{pg} / \mathrm{mL}$ \\
$\mathrm{MN} \mathrm{pg} / \mathrm{mL}$
\end{tabular}

\begin{tabular}{c}
\hline May 2014 \\
\hline 2.64 \\
0.94 \\
39 \\
4.69 \\
12 \\
\\
$328^{\star}$ \\
$15^{\star}$
\end{tabular}

May 2015

$\overline{\text { Dec } 2015}$

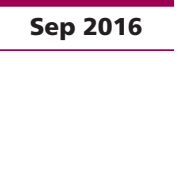

\begin{tabular}{c}
\hline Reference ranges \\
\hline $2.24-2.63$ \\
$0.88-1.45$ \\
$38-48$ \\
$2.5-7.5$
\end{tabular}

PTH pmol/L

$\mathrm{NEnmol} / 24 \mathrm{~h}$

EPInmol/24h

$15^{*}$

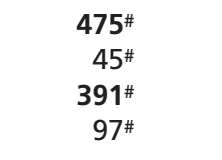

$541^{\#}$
$64^{\#}$
$314^{\#}$
$90^{\#}$

$1.1-7.3$

Abnormal results are in bold

*Performed in Hospital A using liquid chromatography-tandem mass spectrometry (LC-MS/MS) - reference ranges: $\mathrm{NE}<627 \mathrm{nmol} / 24 \mathrm{~h}, \mathrm{EPI}<86 \mathrm{nmol} / 24 \mathrm{~h}$; \#Performed in Hospital B using liquid chromatography-electrochemical detection (LC-ECD) - reference ranges as listed; ** Measured by liquid chromatography-tandem mass spectrometry (LC-MS/MS).

25OHD, 25-hydroxy-vitamin D3; FC, fractionated catecholamines; EPI, epinephrine; NE, norepinephrine; NMN, normetanephrine; MN, metanephrine; PTH, parathyroid hormone. 
Meanwhile, she was incidentally found to have mild hypercalcaemia (Table 1), which the clinical focus was then diverted to. Further workup showed an elevated parathyroid hormone (PTH) level of $12 \mathrm{pmol} / \mathrm{L}$ (reference range: $1.1-7.3 \mathrm{pmol} / \mathrm{L}$ ), which was suggestive of PHPT in the presence of hypercalcaemia. A technetium ( $99 \mathrm{mTc})$ sestamibi scan showed three very faint foci of delayed washout near the lower pole of left thyroid lobe, the midpole of right thyroid lobe and the lower pole of right thyroid lobe (Fig. 2). A neck ultrasonography was suspicious of a 1-cm parathyroid lesion posterior to the right lobe of the thyroid gland. A subsequent $4 \mathrm{D}-\mathrm{CT}$ confirmed the presence of a parathyroid adenoma $(15 \times 4 \times 9 \mathrm{~mm})$ near the mid-pole of right lobe of the thyroid gland (Fig. 3). Minimally invasive right superior parathyroidectomy was performed with intraoperative PTH monitoring in July 2015. A right superior parathyroid adenoma was resected, which was confirmed on surgical pathology. Follow-up biochemical testing revealed normalization of calcium and PTH level.

Our patient returned for scheduled follow-up after the operation and still complained of occasional palpitation. Upon further testing, mildly elevated 24-h urinary norepinephrine (NE) and normetanephrine (NMN) were detected (Table 1), and the suspicion of a PPGL was raised. A CT scan of the adrenals subsequently revealed a $1.9 \mathrm{~cm} \times 1.1 \mathrm{~cm}$ (antero-posterior $\times$ transverse) hypo- to

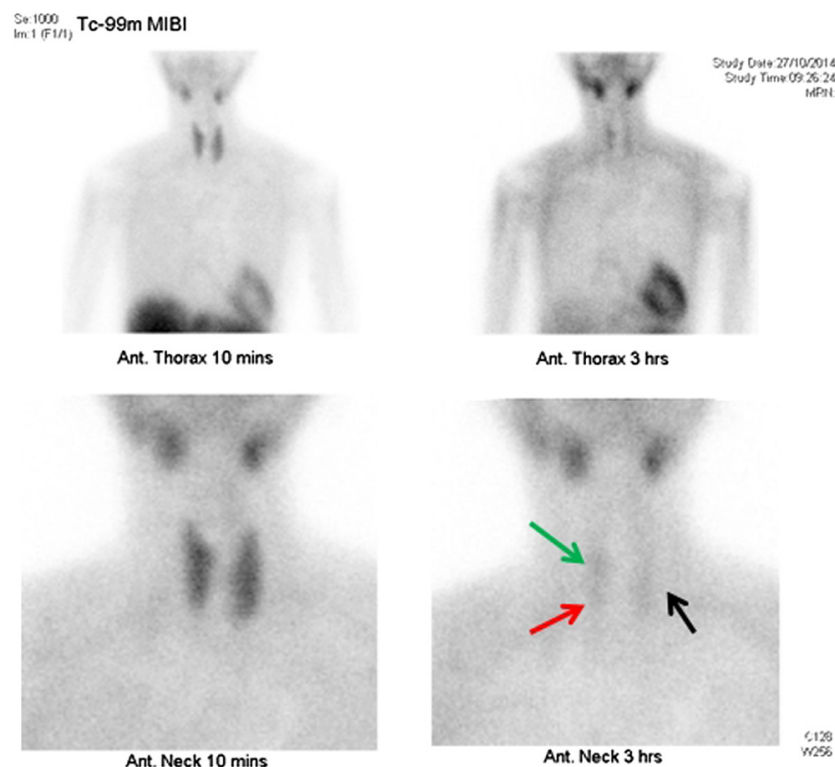

Figure 2

$99 m$ Tc-Sestamibi scan of the patient. There was faint delayed washout near the lower pole of left thyroid lobe (black arrow), the mid-pole of right thyroid lobe (green arrow) and the lower pole of right thyroid lobe (red arrow).

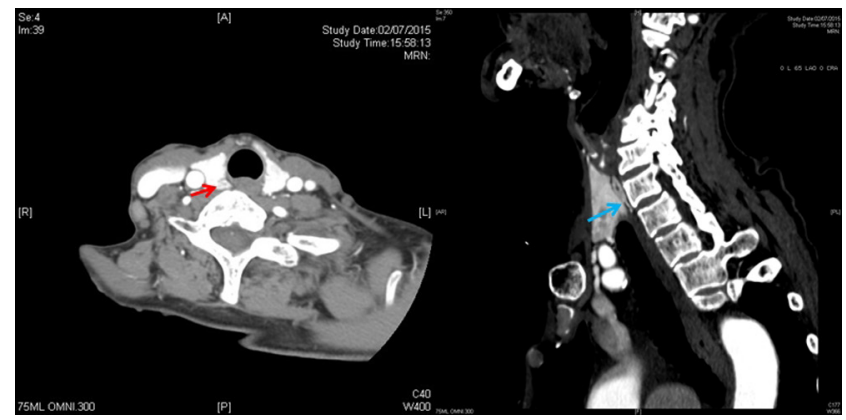

Figure 3

4D-CT of the patient. A $9 \times 4 \times 15 \mathrm{~mm}$ hypodense $(39 \mathrm{HU}$ ) lesion (red arrow) is seen posterior to the upper pole of right lobe of thyroid. It shows early arterial enhancement $(210 \mathrm{HU})(\mathrm{A})$ and shows washout on venous phase $(86 \mathrm{HU})$. Central hypodense centre and polar vessel sign are noted (B) (blue arrow). Enhancement characteristic and imaging features are in keeping with a parathyroid adenoma.

iso-dense lesion over the left adrenal gland. The density of the lesion measured 52 Hounsfield Units (HU) at precontrast scan, $103.4 \mathrm{HU}$ at venous phase and $114 \mathrm{HU}$ at delayed phase (Fig. 4) with an absolute washout less than $60 \%$. These imaging features were not compatible with an adrenal adenoma. A 123I-metaiodobenzylguanidine (MIBG) scintigraphy revealed faint uptake over the left adrenal bed (Fig. 5), which was compatible with a left pheochromocytoma.

Our patient then underwent laparoscopic left adrenalectomy in a tertiary referral centre. Plasma NMN performed preoperatively was elevated as well (Table 1). She was prepared with alpha-blockade using terazocin followed by beta-blockade using propanolol preoperatively. There was mild fluctuation of blood pressure intraoperatively during manipulation of the adrenal tumour with systolic BP up to $190 \mathrm{mmHg}$, which was aborted with remifentanil. The intraoperative

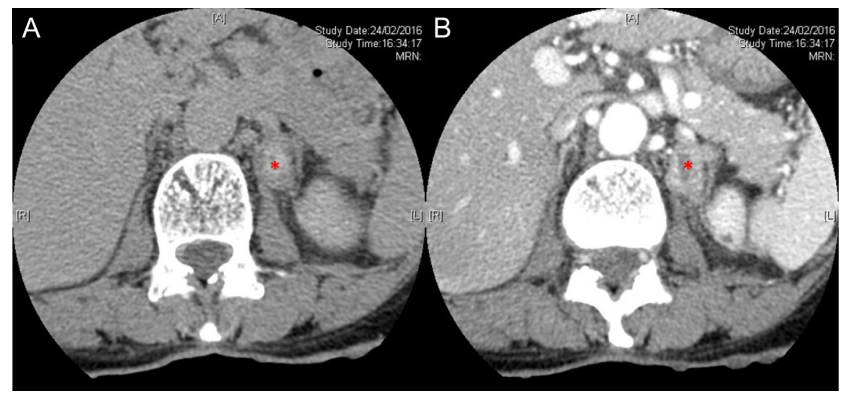

Figure 4

(A) Pre-contrast scan: a non-calcified hypo- to isodense lesion (*) of $1.9 \times 1.1 \mathrm{~cm}$ at the region of the left adrenal. Density measured $51.7 \mathrm{HU}$. (B) Post contrast scan: the density of the lesion measured $103.4 \mathrm{HU}$ at venous phase. The lesion demonstrated delayed enhancement at the central portion, measuring $114 \mathrm{HU}$. The absolute washout was $<60 \%$. 


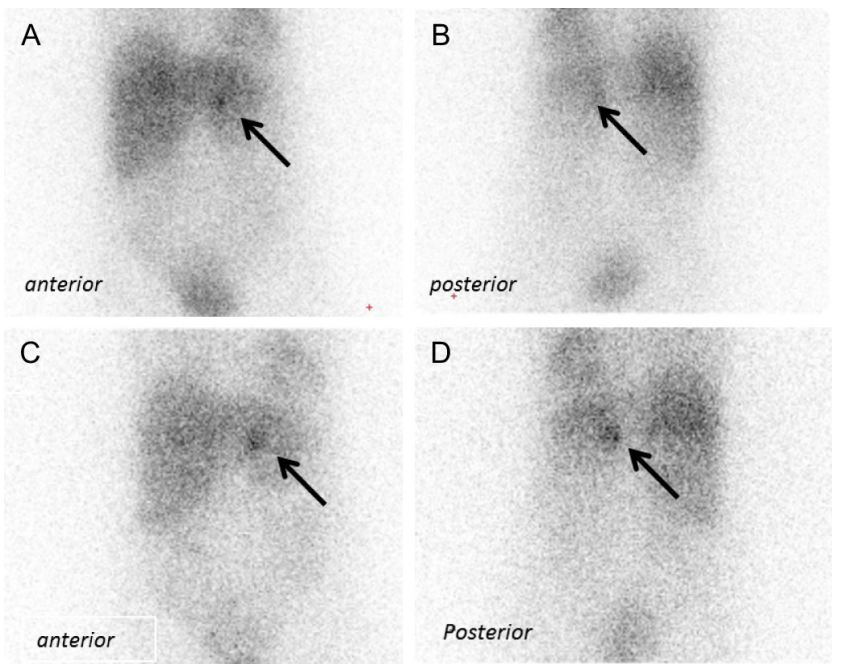

Figure 5

123I-MIBG scan of the patient. (A) and (B) At 24h after 123I-MIBG injection. (C) and (D) At $48 \mathrm{~h}$ post 123I-MIBG injection. Faint uptake was noted at the left adrenal bed (black arrow).

course was otherwise smooth and the patient ran a smooth recovery postoperatively. The surgical specimen confirmed a pheochromocytoma of the left adrenal gland. Symptoms of palpitation and hypertension resolved after the operation. Follow-up biochemical testing revealed normalization of urinary NE and NMN as well as plasma MNM levels. Disease recurrence was not encountered at the latest follow-up in January 2018. Calcium and PTH levels also remained normal upon 2.5 years of follow-up.

\section{Discussion}

Neurofibromatosis type 1 (NF-1) is a dominantly inherited genetic disorder with a birth incidence of 1 in 2500 to 1 in $3000(1,9)$ and is diagnosed based on established clinical criteria $(9,10)$. Apart from the frequently found neurofibromas and optic pathway gliomas, patients with NF-1 are at increased risk of various benign and malignant tumours throughout life, including central nervous system tumours, peripheral nerve sheath tumours, gastrointestinal stromal tumours and leukaemia $(1,9)$. Endocrine diseases and neoplasia also occur in patients with NF-1 which may include PPGLs, PHPT, gastroenteropancreatic neuroendocrine tumour, thyroid and other adrenal tumours $(1,2,5,11,12)$.

Pheochromocytoma is estimated to have a prevalence of $0.1-14 \%$ in NF-1 and may be up to $20-50 \%$ in hypertensive subjects (1, 4, 6, 13). Extra-adrenal paraganglioma (PGL) are uncommon while malignant PPGL may occur up to about $10 \%$ of cases $(4,14)$. A recent large retrospective cohort study by Gruber et al. reported the prevalence of pheochromocytoma was $2.9 \%$ in 1415 patients with NF-1 by using computer search on patient databases (7). On the other hand, two prospective studies where consecutive patients with NF-1 were screened for pheochromycoma showed a much higher prevalence of $7.7 \%$ (13) and $14.6 \%$ (6). Such a large discrepancy is explained by the fact that current guidelines do not recommend routine screening in asymptomatic or normotensive subjects so that reported prevalence rates differed amongst retrospective studies based largely on case finding and prospective studies based on disease screening. Indeed, pheochromocytoma in NF-1 can be entirely asymptomatic and not infrequently present as adrenal incidentaloma. Typical symptoms such as palpitation, headache, hyperhidrosis and paroxysmal hypertension were found in slightly more than half (58\%) of the patients by Gruber et al. (7) while Képénékian et al. reported their presence in 33\% (4 out of 12 patients) only (13). On the other hand, 31, 56 and $100 \%$ of patients were reported to present as adrenal incidentaloma by Gruber et al. (7), Shinall et al. (15) and Mormarco et al. (16) respectively. Nevertheless, the presence of symptoms and/ or hypertension and/or an adrenal incidentaloma should alert the clinician to test for the presence of a PPGL in all subjects with NF-1.

The characteristics of PPGLs in NF-1 also varied amongst different studies. While Shinall et al. reported in their cohort of 56 patients with pheochromocytoma that patients with NF-1 had smaller pheochromocytoma and less hypertension compared with those with sporadic pheochromocytoma (15), the American-European Pheochromocytoma Study Group (14) and Maromarco et al. (16), which included 565 and 145 patients with pheochromocytoma respectively, found that the clinical characteristics of pheochromocytoma in NF-1 were indistinguishable from those of their sporadic counterparts. They also found that patients with NF-1 presented at an older age (mean age 45 years) when compared with other genetically predisposed syndromes (mean age 30 years) $(14,16)$. In addition, the secretory behaviour of pheochromocytoma in NF-1 may be more variable as previously thought. While Eisenhofer et al. suggested that pheochromocytoma in NF-1 mainly secreted epinephrine(EPI)/metanephrine(MN) (17), Gruber et al., Képénékian et al. and Moramarco et al. observed that 
pheochromocytoma in NF-1 could be predominantly or purely NE/NMN secreting and sometimes nonsecretory (MN/NMN less than two times upper limit of normal) $(7,13,16)$. The levels of metanephrines may not correlate well with symptoms though higher levels of metanephrines were generally observed in patients with larger tumours $(7,13)$. Scintingraphy effectively picked up pheochromocytoma in NF-1 with a sensitivity of around $90 \%$ for MIBG scan and almost 100\% for F-DOPAPET-CT $(13,16)$. Therefore, even very modest elevation of metanephrines in any NF-1 patient should be carefully evaluated for the presence of a PPGL, as small tumours may only produce minute excess of metaphrines as exemplified by our patient. In addition, it is recommended to obtain measurement of metanephrines (plasma or urinary) rather than catecholamines as initial biochemical testing of PPGLs due to their superior sensitivities as illustrated in the present case (18).

Although general consensus on screening of pheochromocytoma in asymptomatic and normotensive NF-1 subjects is lacking, emerging data suggest benefit in routine PPGL screening of all individuals with NF-1. The Mayo Clinic group recommended routine case detection testing for all patients with NF1 with plasma-free metanephrines or 24-h urine fractionated metanephrines and catecholamines every 3 years starting from age 10-14 years (7). This is based on the observation that not all patients would present with symptoms, while the three-yearly schedule is considered sufficient compared to the yearly schedule in other familial paraganglioma syndromes of which the prevalence of pheochromocytoma is higher. The cost-effectiveness of such a strategy remains to be tested.

By contrast, the association between PHPT and NF-1 is less clear. Since 1970s, there have been approximately 20 cases of PHPT in NF-1 reported in the literature $(5,8$, $19,20,21,22)$. The mean age of presentation was around 45 years while osteoporosis was a common feature. The majority of patients harboured a solitary parathyroid adenoma or single gland hyperplasia $(8,19)$. In the only population-based cancer registry study where data on parathyroid pathology was available, only 1 out of 71 NF-1 patients had parathyroid adenoma (5). Therefore, given the lack of epidemiological or functional studies, the link between PHPT and NF-1 remains unsubstantiated. Nevertheless, high prevalence of skeletal diseases and metabolic bone defect has been reported in subjects with NF-1 $(1,23,24)$. The presence of PHPT may further exacerbate the bone diseases in these patients and when it is recognised, treatment should be considered based on the current guidelines (25).

Intriguingly, the concurrence of pheochromocytoma and PHPT has also been reported in a few cases $(21,22$, $26,27,28)$. Behera et al. reported a 33-year-old gentleman with NF-1 harbouring both a right pheochromocytoma and a left inferior parathyroid adenoma (21). AL-Wahhabi et al. (22) and Altinova et al. (26) reported two similar patients with NF-1 having bilateral pheochromocytoma and a parathyroid adenoma. Gkaliagkousi et al. (27) and Cotesta et al. (28) both reported the presence of pheochromocytoma, parathyroid adenoma and medullary thyroid carcinoma in patients with NF-1 confirmed by genetic testing, mimicking full-blown picture of MEN-2A. Patients with overlapping features of NF-1 and MEN-2 harbouring both germline mutations on NF1 and RET have also been reported $(29,30)$. Indeed, Diazzi et al. have reported thyroid C-cell hyperplasia and abnormal calcitonin response to pentagastric stimulation in 7 out of 17 patients with NF-1, suggesting a link of NF-1 to thyroid C-cell pathology (31). It has been suggested that NF-1 in association with PHPT and PPGL may be a variant of MEN-2 (20). Despite the above observations, more systemic studies are required to establish whether there exists true relationship between NF-1 and MEN-2.

In conclusion, we herein reported the rare co-occurrence of pheochromocytoma and parathyroid adenoma in a patient with NF-1. This widens the spectrum of endocrine diseases that may be encountered in the management of subjects with NF-1. All NF-1 patients with hypertension or symptoms suggestive of PPGL should undergo biochemical testing by plasma free or urinary fractionated metanephrines and any elevated values should be carefully followed and investigated. The association between PHPT and NF-1, and that between NF-1 and MEN-2, remains at best plausible and need to be further elucidated with systemic and functional studies.

\section{Declaration of interest}

The authors declare that there is no conflict of interest that could be perceived as prejudicing the impartiality of the research reported.

\section{Funding}

This research did not receive any specific grant from any funding agency in the public, commercial or not-for-profit sector. 


\section{Patient consent}

Written informed consent has been obtained from the patient for the publication of the submitted article and accompanying images.

\section{Author contribution statement}

Both Dr Tam V H K and Dr Fok C K have made significant contribution to the overall management of the patient and the proof-reading of the manuscript.

\section{References}

1 Hirbe AC \& Gutmann DH. Neurofibromatosis type 1: a multidisciplinary approach to care. Lancet Neurology 201413 834-843. (https://doi.org/10.1016/S1474-4422(14)70063-8)

2 Kiuru M \& Busam KJ. The NF1 gene in tumor syndromes and melanoma. Laboratory Investigation 201797 146-157. (https://doi. org/10.1038/labinvest.2016.142)

3 Ratner N \& Miller SJ. A RASopathy gene commonly mutated in cancer: the neurofibromatosis type 1 tumour suppressor. Nature Reviews Cancer 201515 290-301. (https://doi.org/10.1038/nrc3911)

4 Walther MM, Herring J, Enquist E, Keiser HR \& Linehan WM. von Recklinghausen's disease and pheochromocytomas. Journal of Urology 1999162 1582-1586. (https://doi.org/10.1016/S00225347(05)68171-2)

5 Zöller M, Rembeck B, Odén A, Samuelsson M \& Angervall L. Malignant and benign tumours in patients with neurofibromatosis type 1 in a defined Swedish population. American Cancer Society 199779 2125-2131. (https://doi.org/10.1002/(SICI)10970142(19970601)79:11<2125::AID-CNCR9>3.0.CO;2-N)

6 Zinnamosca L, Petramala L, Cotesta D, Marinelli C, Schina M, Cianci R, Giustini S, Sciomer S, Anastasi E, Calvieri S, et al. Neurofibromatosis type 1 (NF1) and pheochromocytoma: prevalence, clinical and cardiovascular aspects. Archives of Dermatological Research 2011303 317-325. (https://doi.org/10.1007/ s00403-010-1090-z)

7 Gruber LM, Erickson D, Babovic-Vuksanovic D, Thompson GB, Young WF Jr \& Bancos I. Pheochromocytoma and paraganglioma in patients with neurofibromatosis type 1. Clinical Endocrinology 2017 86 141-149. (https://doi.org/10.1111/cen.13163)

8 Austin E \& Bates A. Association of neurofibromatosis type 1 with primary hyperparathyroidism: report of a case. Endocrine Abstracts 201644 EP25. (https://doi.org/10.1530/endoabs.44.EP25)

9 Ferner RE, Huson SM, Thomas N, Moss C, Willshaw H, Evans DG, Upadhyaya M, Towers R, Gleeson M, Steiger C, et al. Guidelines for the diagnosis and management of individuals with neurofibromatosis 1. Journal of Medical Genetics 200744 81-88. (https://doi.org/10.1136/jmg.2006.045906)

10 National Institutes of Health Consensus Development Conference Statement: neurofibromatosis. Archives of Neurology 198845 575-578.

11 Patil S \& Chamberlain RS. Neoplasms associated with germline and somatic NF1 gene mutations. Oncologist 201217 101-116. (https:// doi.org/10.1634/theoncologist.2010-0181)

12 Menon RK, Ferrau F, Kurzawinski TR, Rumsby G, Freeman A, Amin Z, Korbonits M \& Chung T-TLL. Adrenal cancer in neurofibromatosis type 1: case report and DNA analysis. Endocrinology, Diabetes and Metabolism Case Reports 20142014 140074. (https://doi.org/10.1530/ EDM-14-0074)

13 Képénékian L, Mognetti T, Lifante JC, Giraudet AL, Houzard C, Pinson S, Borson-Chazot F \& Combemale P. Interest of systematic screening of pheochromocytoma in patients with neurofibromatosis type 1. European Journal of Endocrinology 2016175 335-344. (https:// doi.org/10.1530/EJE-16-0233)
14 Bausch B, Borozdin W, Neumann HP \& European-American Pheochromocytoma Study Group. Clinical and genetic characteristics of patients with neurofibromatosis type 1 and pheochromocytoma. New England Journal of Medicine 2006354 2729-2731. (https://doi.org/10.1056/NEJMc066006)

15 Shinall MC \& Solórzano CC. Pheochromocytoma in neurofibromatosis type 1: when should it be suspected? Endocrine Practice 201420 792-796. (https://doi.org/10.4158/EP13417.OR)

16 Moramarco J, El Ghorayeb N, Dumas N, Nolet S, Boulanger L, Burnichon N, Lacroix A, Elhaffaf Z, Gimenez Roqueplo AP, Hamet P, et al. Pheochromocytomas are diagnosed incidentally and at older age in neurofibromatosis type 1. Clinical Endocrinology 201786 332-339. (https://doi.org/10.1111/cen.13265)

17 Eisenhofer G, Lenders JW, Timmers H, Mannelli M, Grebe SK, Hofbauer LC, Bornstein SR, Tiebel O, Adams K, Bratslavsky G, et al. Measurements of plasma methoxytyramine, normetanephrine, and metanephrine as discriminators of different hereditary forms of pheochromocytoma. Clinical Chemistry 201157 411-420. (https:// doi.org/10.1373/clinchem.2010.153320)

18 Lenders JW, Duh QY, Eisenhofer G, Gimenez-Roqueplo AP, Grebe SK, Murad MH, Naruse M, Pacak K, Young WF Jr \& Endocrine Society. Pheochromocytoma and paraganglioma: an Endocrine Society Clinical Practice Guideline. Journal of Clinical Endocrinology and Metabolism 2014 99 1915-1942. (https://doi.org/10.1210/jc.2014-1498)

19 Chakrabarti S, Murugesan A \& Arida EJ. The association of neurofibromatosis and hyperparathyroidism. American Journal of Surgery 1979137 417-420. (https://doi.org/10.1016/00029610(79)90079-5)

20 Favere AM, Tsukumo DM, Matos PS, Santos SL \& Lalli CA. Association between atypical parathyroid adenoma and neurofibromatosis. Archives of Endocrinology and Metabolism 201559 460-466. (https://doi.org/10.1590/2359-3997000000092)

21 Behera KK, Nanaiah A, Gupta A \& Rajaratnam S. Neurofibromatosis type 1 , pheochromocytoma with primary hyperparathyroidism: a rare association. Indian Journal of Endocrinology and Metabolism 2013 17 349-351. (https://doi.org/10.4103/2230-8210.109670)

22 Al-Wahhabi B. Parathyroid adenoma and bilateral pheochromocytoma in a patient with neurofibromatosis. Annals of Saudi Medicine 25 255-257.

23 Lodish MB, Dagalakis U, Sinaii N, Bornstein E, Kim A, Lokie KB, Baldwin AM, Reynolds JC, Dombi E, Stratakis CA, et al. Bone mineral density in children and young adults with neurofibromatosis type 1 . Endocrine-Related Cancer 201219 817-825. (https://doi.org/10.1530/ ERC-12-0293)

24 Brunetti-Pierr N, Doty SB, Hicks J, Phan K, Mendoza-Londono R, Blazo M, Tran A, Carter S, Lewis RA, Plon SE, et al. Generalized metabolic bone disease in neurofibromatosis type I. Molecular Genetics and Metabolism 200894 105-111. (https://doi.org/10.1016/j. ymgme.2007.12.004)

25 Bilezikian P1, Brandi ML, Eastell R, Silverberg SJ, Udelsman R, Marcocci C \& Potts JT Jr. Guidelines for the management of asymptomatic primary hyperparathyroidism: summary statement from the Fourth International Workshop. Journal of Clinical Endocrinology and Metabolism 201499 3561-3569. (https://doi. org/10.1210/jc.2014-1413)

26 Altinova AE, Toruner FA, Cimen R, Karakoc A, Atasever T, Yetkin I, Ayvaz G, Cakir N \& Arslan M. The association of neurofibromatosis, bilateral pheochromocytoma and primary hyperparathyroidism. Experimental and Clinical Endocrinology and Diabetes 2007115 468-470. (https://doi.org/10.1055/s-2007-981661)

27 Gkaliagkousi E, Erlic Z, Petidis K, Semertzidis P, Doumas M, Zamboulis C, Neumann HP \& Douma S. Neurofibromatosis type 1: should we screen for other genetic syndromes? A case report of co-existence with multiple endocrine neoplasia 2A. European Journal of Clinical Investigation 200939 828-832. (https://doi.org/10.1111/ j.1365-2362.2009.02174.x) 
28 Cotesta D, Erlic Z, Petramala L, Verrienti A, Cavallaro G, Giustini S Divona L, Polistena A, Ciardi A, D'Erasmo E, et al. Coincidence of neurofibromatosis type 1 and multiple endocrine neoplasia type 2 (MEN 2). Endocrinologist 200818 277-281. (https://doi.org/10.1097/ TEN.0b013e3181913188)

29 Ercolino T, Lai R, Giachè V, Melchionda S, Carella M, Delitala A, Mannelli M \& Fanciulli G. Patient affected by neurofibromatosis type 1 and thyroid C-cell hyperplasia harboring pathogenic germ-line mutations in both NF1 and RET genes. Gene 2014536 332-335. (https://doi.org/10.1016/j.gene.2013.12.003)

30 Mon A, Malipatil N, Sharma D, Afta R, Koay Y, Whittingham P, Hamilton A \& Vora J. A patient with neurofibromatosis type-1 (NF1) Abstracts 200919 P175.

31 Diazzi C, Guidi A, Luberto A, Taliani E, Madeo B, Rochira V \& Carani $C$. Thyroid disease in patients with type- 1 neurofibromatosis: an underestimated issue? Endocrine Abstracts 201126 P452.

Received in final form 20 February 2018

Accepted 6 March 2018 